\title{
Peer actions for a Service Learning project to prevent drug- facilitated sexual assaults
}

Gloria Quintanilla ${ }^{1}$, Fernando E. Ortega-Ojeda ${ }^{2}$, Carmen García-Ruiz ${ }^{3}$, Pablo PregoMeleiro $^{3}$, Carmen Figueroa Navarro ${ }^{4}$, Begoña Bravo-Serrano ${ }^{3,5}$, María Ruth GarcíaPernía $^{6}$, Felix Zapata ${ }^{3}$, María José González-Muñoz ${ }^{7}$, Carmen J. Mateos-Vega ${ }^{7}$, Gemma Montalvo ${ }^{3, *}$

${ }^{1}$ Dept.Organic and Inorganic Chemistry, University of Alcalá (UAH) and University Institute for Research in Police Sciences (IUICP), Spain, ${ }^{2}$ Dept. Physics and Mathematics, UAH-IUICP, Spain, ${ }^{3}$ Dept. Analytical Chemistry, Physical Chemistry and Chemical Engineering, UAHIUICP, Spain, ${ }^{4}$ Dept. Legal Sciences, UAH-IUICP, Spain, ${ }^{5}$ National Institute of Toxicology and Forensic Science, Spain, ${ }^{6}$ Dept. Philology, Communication and Documentation, UAH, Spain, ${ }^{7}$ Dept. Biomedical Sciences, UAH, Spain. ${ }^{*}$ Corresponding author: gemma.montalvo@uah.es

\begin{abstract}
The service-learning methodology combines active learning processes and community service. This service-learning experience was performed using an interdisciplinary and cross plan. The teachers made a horizontal coordination in the courses, and a vertical coordination in subjects of the Degrees involved. This allowed working together in the students' curricular training process. It also permitted covering various specific skills, as corresponds to the different subjects, whilst optimizing the students' workload.
\end{abstract}

The service addressed the problem of Drug-Facilitated Sexual Assaults (DFSA) in the youth leisure nightlife. An active learning about the problem was encouraged in the classroom, focused on recognizing myths, attitudes, and risk situations.

The service-learning actions to the community was based on an anonymous survey conducted among the students, which dealt with the problem. The Service Learning was stimulated through the design, planning and development of activities aimed at gaining social awareness of the existing problem while favouring peer learning processes.

The students undertook awareness actions at different levels, spreading their message by means of social networks, high school workshops, and information stands on the street.

Keywords: Service Learning; peer actions; interdisciplinary; horizontal and vertical coordinations; Drug-Facilitated Sexual Assaults (DFSA). 


\section{Introduction}

The Service Learning methodology combines active learning processes and community service. As in any Service Learning project, the students apply the topics they studied to the real needs of their environment in order to improve it (Red Española Aprendizaje-Servicio, 2020). These experiences have already been applied at different educational levels (Santos Rego, Sotelino Losada, \& Lorenzo Moledo, 2016), and in the university case, they must be considered as civic missions to fulfil (Santos, Sotelino Losada, \& Lorenzo Moledo, 2015) and favour its institutional performance.

With this methodology, the students develop a solidarity project that unites knowledge, skills, attitudes, and values related to the educational practice developed in a specific subject. Therefore, it is about curriculum competencies with emphasis on acquiring skills on the social and citizen sphere.

Furthermore, the values that this type of work bring to the students include also the acquisition of pro-social attitudes (commitment to the environment) and life (strengthens social abilities) values and skills. The students realize that they can change their environment, so the Service Learning renders a more effective learning. Consequently, the Service Learning methodology is a tool that improves the educational success and social cohesion.

A Service Learning project can be applied to any subject and environment. This is because any service project is valid as long as it recovers the social sense of education and reinforces the acquisition of knowledge in any discipline. Therefore, the Service Learning should focus on the addressed students, establishing learning activities related to their curricula, providing them with teaching support. This way, the students learn how to reflect and develop diagnose abilities regarding problems in their environment. As a result, they will be able to define a service that they consider socially necessary, and in which they would feel involved.

The teaching team of this project, combining their teaching and research experience, began last year with a Service Learning action on the topic of Drug-Facilitated Sexual Assaults (DFSA, also-known-as Chemical Submission). We understand DFSA as the temporary disability of a person caused by a decrease in her/his volitional and cognitive abilities due to the voluntary or involuntary consumption of psychoactive substance (alcohol and/or illegal or prescription drugs). Since 2010, the National Institute of Toxicology and Forensic Sciences has detected alleged crimes committed through DFSA and concerned psychoactive substances used to nullify the will of the victim (García-Caballero, CruzLandeira, \& Quintela-Jorge, 2014). 
Therefore, the teaching team has identified the young university students as a kind of population at maximum risk. From this analysis, as university educators, we value the importance and need to work on prevention and information with these young people, which are at the same time potential victims and part of the solution for the DFSA problems.

This problem of DFSA has a huge impact on the mass media which includes written press, television, radio or the Internet. Cases as spread as "La Manada" or "The False Shaman", show the attention that DFSA has received in Spain, even to the point that many countries alert their citizens to this threat when traveling to Spain. At the same time, the media and society show a lack of reflection and comprehensive action regarding the problem.

But, above all, this problem occurs globally (Anderson et al., 2017; European Monitoring Centre for Drugs and Drug Addiction [EMCDDA], 2008; McBrierty et al., 2013; Tiemensma \& Davies, 2018), affecting from the lack of knowledge regarding the problem, the possible vulnerability of various population groups, the gender equality and respect for people, to other scenarios such as primary and hospital care. It is in these care places where early and adequate samplings are key factors in confirming a diagnosis (García-Repetto \& Soria, 2011). This problem also affects the clinical-forensic laboratories (Marc, 2008), which need better detection methods for those involved legal or illegal aubstances, which now belong to a frequent consumption pattern in our society (García-Caballero et al., 2014). The problem also concerns the psychological support of those affected by the posttraumatic effect, or to therapists who facilitate the recovery of the balance and self-esteem of the victims. The DFSA also touch the police and judicial systems responsible for fighting them. This holistic view of the problem clearly shows that the detection, visualization, conflict resolution, and fight against DFSA.

Since the 2017/18 academic year, different teachers from various disciplines have considered the opportunity to collaborate in teaching strategies that would allow us to approach the current social issue affecting our young university students. The selected students will be future professionals with a high social impact.

This Service Learning experience carries out an interdisciplinary and transversal work in order to improve the social service and the students' education in general competences reinforced from other disciplines, and a vertical coordination in the Degrees' subjects. This allowed the teachers to work together in the students' curricular development process, and favouring that the students cover the specific skills on the different subjects.

For all the above, the involved teachers focussed on the need of the future professionals, now students at the University of Alcalá, for awareness, action capacity, and service to the society. This project was tackled in coordinated sequential stages, where the active learning actions were guided by the teaching staff. In the first stage, the students acquired the 
curricular knowledge, critical judgment skills, and communication skills on the subject. The second phase was based on a Service Learning action on the community, proposing activities aiming at an education that would prevent the risk behaviours triggering DFSA.

\section{Objective}

The aim of this project is to implement a peer action for a Service Learning strategy on the Drug-Facilitated Sexual Assaults topic, integrating knowledge with interdisciplinary collaborative actions in three Bachelor Degrees at the University of Alcalá (UAH), Spain. For achieving this aim, the four specific proposals were:

a) performing a horizontal, vertical, and interdisciplinary coordination between the university teachers, that optimizes the student workload;

b) using virtual tools for the project implementation;

c) training students as active citizens and providing opportunities to apply and enhance other generic competencies for science students; and

d) improving of the teaching capacities of the involved academic staff.

\section{Project Development}

\subsection{Framework and involved agents}

This Service Learning project implicated seven subjects of three Bachelor Degrees at the University of Alcalá (Spain), during the 2018/19 academic year:

- $\quad$ Chemistry $\left(1^{\text {st }}\right.$ year, 1Semester (S)), History and Fundamentals of Criminalistics and Criminology $\left(1^{\text {st }}, 1 \mathrm{~S}\right)$, Communication Techniques $\left(1^{\text {st }}, 1 \mathrm{~S}\right)$, and Forensic Instrumental Analysis ( $\left.2^{\text {nd }}, 2 \mathrm{~S}\right)$ in the Degree in Criminalistics: Forensic Sciences and Technologies.

- $\quad$ Principles of Physics and Biophysics $\left(1^{\text {st }}, 1 \mathrm{~S}\right)$ and Study and Prevention of Drug Dependencies $\left(5^{\text {th }}, 1 \mathrm{~S}\right)$ in the Degree in Pharmacy.

- $\quad$ Chemistry $\left(1^{\text {st }}, 1 \mathrm{~S}\right)$ in the Degree in Health Biology.

During the preparation of this project, the teacher team analysed and defined the interest topic, working on the definitions of the pedagogical aspects, and planned the management and organization of the project. This was achieved during a presential meeting of the teacher team at the beginning of the course and, then, by email and using a shared course named "Chemical Submission" in the WebCT virtual platform of the UAH, where the different initiatives were collected and shared. The teaching team coordination was made to promote the integration of interdisciplinary knowledge between teachers firstly, and then to the students. This coordination was developed in the three working dimensions: (i) horizontal (coordination between the three subjects of the same course in the Degree in 
Criminalistics: Forensic Sciences and Technologies); (ii) vertical (coordination between the subjects of the Pharmacy and Criminalistics: Forensic Sciences and Technologies degrees); and (iii) interdisciplinary (holistic view of the DFSA problem by working together the chemical, toxicological (both in Health Biology degree), and legal aspects or message communication between the subjects from the different areas and degrees involved).

The coordinator had a key role during this horizontal and vertical coordination, not only for the collaborative messages sent to all, but also for using different tools (i.e., shared documents) to work cooperatively among the different academic memebers involved.

Additionally, in each subject, the teacher had the autonomy to monitor the students through face-to-face seminars or through the WebCT virtual platform of UAH, with recommended websites and YouTube videos. This applied methodology of virtual monitoring is consistent with the characteristics of the current university students, adapted to the change in the reasoning and learning methodologies more oriented to new technological resources.

In the involved subjects, the students enrolled annually usually exceed 70 per subject. Therefore, the teaching team relied on flipped classroom strategies for the work with the students. Hence, the students also had access to the reports presented by other participants in the shared course in the WebCT virtual platform of UAH. This project, selected as of institutional interest, pursued the following competencies in the students: (i) promote the cooperative and collaborative work among different degrees; (ii) enhance the critical thinking skills (analyze the studied material); (iii) increase the ability to organize and share information; and (iv) improve the communication skills. Consequently, this experience increased the students involvement in their learning process and social commitment.

\subsection{Student approach to the project}

To start getting involved in the DFSA topic, the students answered an anonymous and ethical survey (Google Forms).

Next, a joint initial meeting of all the Degrees was held to favour the active learning of the students of different degrees. This allowed highlighting the importance of the integrated knowledge and the transversal actions that they will later propose to carry out. Besides, it also served to point out the Service Learning related to each subject. The speaker in this initial session was a young researcher enrolled in a pre-doctoral Training for University Teacher programme at the UAH. This way, it is evidenced what a "peer learning" is, which is one of the objectives of this Service Learning proposal.

The results of the initial survey, analysed by the teaching team, were shared with the students as an initial element of motivation and analysis of the DFSA problem. It also helped to identify false myths propagated by the media (which enlarge the problem) and served as a tool for designing and building their preventive actions. 
The students, organized in groups of up to 10 people, investigated the DFSA problem, planned and designed, as teamwork, a social service they considered interesting and important. Thus, the students became protagonists in prevention and detection of risk situations, in solidarity with other youth groups. In this process, the teachers assisted as counsellors and facilitators for the students in their respective subjects, guiding them in defining their own service projects following a conventional methodology.

\subsection{Service Learning actions}

The different groups of students, organized by subjects and the corresponding degrees, defined their own service actions.As result, the awareness actions of the studentes included initiatives in various social networks (i.e., https:/www.instagram.com/sumisionquimica/, 330 followers; https://www.instagram.com/sumisionquimica_uah/?hl=es, 987 followers), their own blogs and several websites for collecting and disseminating the peers work in the university and high school education fields, videos (i.e., https://www.youtube.com/watch?v=U4bWR5FLkbY $\quad(1.059 \quad$ views $)$; https://www.youtube.com/watch?v=EOx4XoVQZ9A views); https://www.youtube.com/watch?v=I-cAmU5S4z0 (196 views)), etc. In those media, the students were from screenwriters to actors, directors and filmmakers. They also carried out numerous talks, as well as awareness campaigns in the street.

From all those activities one stands out: the visits to Secondary Schools, which was carried out during the last three academic years. In these events, various university teachers and students involved in the project gave DFSA-related talks to those institutions' students. These workshops reached a large number of very implicated students belonging to 1st and 2nd bachelor courses. An example is the visit to the IES Cardenal Cisneros in Alcalá de Henares (Madrid, Spain), where about 150 students took part from a total of 540 students of the School. Later, the participants used the philosophy of "peer actions" to give adequated talks to younger students of about 12-13 years old. These younger listeners are at the present in higher risky situation, thus, it was crucial to make them aware of this important danger. This experience has been extended more than 20 Secondary Schools in the Community of Madrid.

Memory of all the acctions were shared in the common course in the WebCT virtual platform of UAH.

\subsection{Evaluation}

Given the curricular nature, the Service Learning actions were evaluated, according to the subject, by means of the students reports and/ or public presentations. The teachers evaluated the development of cross skills, actions creativity, and impact with quantifiable evidence. The educators also assessed the students analysis and critical judgment, synthesis, 
argumentation, and communication skills, in addition to their specific competencies regarding the corresponding subjects.

In addition, the students completed an evaluation wheel as a self-assessment and heteroevaluation among the students of each group. Those evaluations were collected through the virtual classroom, to centralize the learning results and have them as evidence for the activity evaluation. The students valued this Service Learning experience very positively.

\section{Impact}

The Service Learning methodology involves the students' active and social learning, as well as their empowerment. In addition, it has a positive impact on the professional development of the teachers because it gives them greater stimulus and satisfaction as well as experience in the implementation of new methodologies and technologies in their teaching practice. Moreover, it also affects positively on the training and active learning of the students since it brings them greater involvement, improvement of their significant learning to better consolidate DFSA-related knowledge, and in the development of their competencies. Some aptitudes they gain are team work and autonomy, critical thinking, interdisciplinary interaction with other students, ability to communicate and an increased social involvement as agents of change and social improvement.

Service Learning, besides supporting the students at their curricular level, achieves their training as citizens capable of changing their environment, and realising that the experience and knowledge they acquire are useful for the community.

On the other hand, it is worth mentioning that this is a multi- and interdisciplinary proposal, which allowed a horizontal coordination of the competencies. At the same time, it permits optimizing the student's workload between different subjects of the same course associated with various knowledge areas. Hence, we consider that it has a wider impact on the students' significant learning.

Another aspect of interest of this proposal is the interrelationship between different subjects and teachers from various faculties. This represents one of the strengths of the project, together with the participation of young researchers.

\section{Conclusions and Future Proposals}

Teachers in general and university educators in particular, play a key role in Service Learning projects. This is because we ourselves must be open to leaving our comfort area and face the learning process from social challenges that require educational intervention. Consequently, it is necessary to be receptive and recognize concrete social problems and challenges, meeting associations and committed people, having a constructive vision of the 
world in which we live, and to be ready to contribute to social changes whilst being able to join curricular elements and social problems.

The university context also encourages scientific research, thus promoting research involving social impact issues will allow transforming the world: making it better. This objective ought to be prioritized while performing research at the institutional, regional, national, and international levels.

Carrying out a Service Learning project does not only generate social benefits but great personal and professional well-being for both the teachers and the participating students.

\section{Acknowledgments}

Teaching Innovation projects UAH / EV951 and UAH / EV1024 of the University of Alcalá; Research project MSCBS-PNSD-2018I032 of the Ministry of Health Consumption and Social Welfare, National Drug Plan; IUICP2019/06 Research project of the University Institute of Police Science Research. P. Prego-Meleiro and F. Zapata thank the UAH for their scholarships.

\section{References}

Anderson L. A., Flynn A., Pilgrim J. L. (2017) A global epidemiological perspective on the toxicology of drug-facilitated sexual assault: A systematic review, Journal of Forensic and Legal Medicine 4, 46-54. https://doi.org/10.1016/j.jflm.2017.02.005.

European Monitoring Centre for Drugs and Drug Addiction, EMCDDA, (2008) from http://www.emcdda.europa.eu/attachements.cfm/att_50544_EN_TDS_sexual_assault.pdf

García-Caballero, C., Cruz-Landeira, A., \& Quintela-Jorge, O. (2014). Sumisión química en casos de presuntos delitos contra la libertad sexual analizados en el Instituto Nacional de Toxicología y Ciencias Forenses (Departamento de Madrid) durante los años 2010, 2011 y 2012. Revista Española de Medicina Legal, 40(1), 11-18.

García-Repetto, R., \& Soria, M. L. (2011). Sumisión química: reto para el toxicólogo forense. Revista Española de Medicina Legal, 37(3), 105-112.

Marc, B. (2008). Current clinical aspects of drug-facillitated sexual assaults in sexually abused victims examined in a forensic emergency unit. Ther Drug Monit, 30(2), 218-24.

McBrierty, D., Wilkinson, A., Tormey, W., (2013) A review of drug-facilitated sexual assault evidence: An Irish perspective. Journal of Forensic and Legal Medicine 20(4),189-97. doi: 10.1016/j.jflm.2012.09.009.

Red Española Aprendizaje-Servicio. (2020). ¿Qué es ApS? Retrieved April 9, 2020, from https://aprendizajeservicio.net/bienvenida/

Santos, M. A., Sotelino Losada, A., \& Lorenzo Moledo, M. (2015). Aprendizaje-Servicio y visión cívica de la universidad. Una propuesta de desarrollo: Editorial Octaedro. 
Santos Rego, M. A., Sotelino Losada, A., \& Lorenzo Moledo, M. (2016). Aprendizaje Servicio e Innovación en la Universidad. Actas VII congreso. nacional y II Internacional de Aprendizaje-Servicio Universitario: Universidad de Santiago de Compostela.

Tiemensma M, \& Davies B. (2018). Investigating drug-facilitated sexual assault at a dedicated forensic centre in Cape Town, South Africa. Forensic Science International, 288,115-122. 